\title{
Smoking and the risk of prostate cancer in the European Prospective Investigation into Cancer and Nutrition
}

S Rohrmann ${ }^{*}, 1,2$, J Linseisen ${ }^{2,3}$, N Allen ${ }^{4}, \mathrm{H}$ B Bueno-de-Mesquita ${ }^{5,6}, \mathrm{~N}$ F Johnsen ${ }^{7}$, A Tjønneland ${ }^{7}$, K Overvad $^{8}$, R Kaaks ${ }^{2}$, B Teucher ${ }^{2}$, H Boeing ${ }^{9}$, T Pischon 9,10, P Lagiou 11,12,13, A Trichopoulou ${ }^{11,14}$, $D$ Trichopoulos ${ }^{12,13}, \mathrm{D}$ Palli ${ }^{15}$, Vittorio Krogh ${ }^{16}, \mathrm{R}_{\text {Tumino }}{ }^{17}, \mathrm{~F} \mathrm{Ricceri}^{18}, \mathrm{M} \vee$ Argüelles Suárez ${ }^{19}$, A Agudo $^{20}$, M-J Sánchez ${ }^{21,22}$, M-D Chirlaque ${ }^{22,23}$, A Barricarte ${ }^{22,24}$, N Larrañaga ${ }^{22,25}$, H Boshuizen ${ }^{5,26}$, H J van Kranen ${ }^{5}$, P Stattin ${ }^{27,28}$, M Johansson ${ }^{27,29}$, A Bjartell ${ }^{30}$, D Ulmert ${ }^{30}$, K-T Khaw ${ }^{31}$, N J Wareham ${ }^{32}$, Pietro Ferrari ${ }^{29}$, I Romieux ${ }^{29}$, M J R Gunter ${ }^{33}$, Elio Riboli ${ }^{33}$ and T J Key ${ }^{4}$

${ }^{1}$ Division of Cancer Epidemiology and Prevention, Institute of Social and Preventive Medicine, University of Zurich, Zurich 8001, Switzerland; ${ }^{2}$ Division of Cancer Epidemiology, German Cancer Research Center (DKFZ), Heidelberg, Germany; ${ }^{3}$ Institute of Epidemiology I, Helmholtz Center Munich, Neuherberg, Germany; ${ }^{4}$ Cancer Epidemiology Unit, University of Oxford, Oxford, UK; ${ }^{5}$ National Institute for Public Health and the Environment (RIVM), Bilthoven, The Netherlands; ${ }^{6}$ Department of Gastroenterology and Hepatology, University Medical Centre, Utrecht, The Netherlands; ${ }^{7}$ Diet, Cancer and Health, Danish Cancer Society, Copenhagen, Denmark; ${ }^{8}$ Department of Epidemiology, School of Public Health, Aarhus University, Aarhus, Denmark; ${ }^{9}$ Department of Epidemiology, German Institute of Human Nutrition Potsdam-Rehbrücke, Nuthetal, Germany; ${ }^{10}$ Molecular Epidemiology Group, Max Delbrueck Center for Molecular Medicine (MDC), Berlin-Buch, Germany; ${ }^{11}$ Department of Hygiene, Epidemiology and Medical Statistics, WHO Collaborating Center for Food and Nutrition Policies, University of Athens Medical School, Athens, Greece; ${ }^{12}$ Department of Epidemiology, Harvard School of Public Health, Boston, MA, USA; ${ }^{13}$ Bureau of Epidemiologic Research, Academy of Athens, Athens, Greece; ${ }^{14} \mathrm{Hellenic} \mathrm{Health} \mathrm{Foundation,}$ Athens, Greece; ${ }^{15}$ Molecular and Nutritional Epidemiology Unit, Cancer Research and Prevention Institute (ISPO), Florence, Italy; ${ }^{16}$ Nutritional Epidemiology Unit, Fondazione IRCCS Istituto Nazionale Tumori, Milano, Italy; ${ }^{17}$ Cancer Registry and Histopathology Unit, 'Civile MP Arezzo' Hospital, Ragusa, Italy; ${ }^{18}$ Human Genetics Foundation (HuGeF), Turin, Italy; ${ }^{19}$ Public Health Directorate, Asturias, Spain; ${ }^{20}$ Unit of Nutrition, Environment and Cancer (UNEC), Cancer Epidemiology Research Program, Catalan Institute of Oncology (ICO), Barcelona, Spain; ${ }^{21}$ Andalusian School of Public Health, Granada, Spain; ${ }^{22}$ Consortium for Biomedical Research in Epidemiology and Public Health (CIBER Epidemiología y Salud Pública-CIBERESP), Pamplona, Spain; ${ }^{23}$ Department of Epidemiology, Murcia Regional Health Authority, Murcia, Spain; ${ }^{24}$ Navarre Public Health Institute, Pamplona, Spain; ${ }^{25}$ Public Health Department of Gipuzkoa, Basque Government, San Sebastian, Spain; ${ }^{26}$ Division of Human Nutrition, Wageningen University, Wageningen, The Netherlands; ${ }^{27}$ Department of Surgery and Perioperative Sciences, Urology and Andrology, Umeå University, Umeå, Sweden; ${ }^{28}$ Department of Surgery, Urology Service, Memorial Sloan-Kettering Cancer Center, New York, NY, USA; ${ }^{29}$ International Agency for Research on Cancer, Lyon, France; ${ }^{30}$ Department of Urology, Skåne University Hospital, Malmö, Sweden; ${ }^{31}$ Department of Public Health and Primary Care, University of Cambridge, Cambridge, UK; ${ }^{32}$ Medical Research Council (MRC) Epidemiology Unit, Cambridge, UK and ${ }^{33}$ School of Public Health, Imperial College London, London, UK

Background: Smoking is not associated with prostate cancer incidence in most studies, but associations between smoking and fatal prostate cancer have been reported.

Methods: During 1992 and 2000, lifestyle information was assessed via questionnaires and personal interview in a cohort of 145112 European men. Until 2009, 4623 incident cases of prostate cancer were identified, including 1517 cases of low-grade, 396 cases of high grade, 1516 cases of localised, 808 cases of advanced disease, and 432 fatal cases. Multivariable Cox proportional hazards regression models were used to examine the association of smoking status, smoking intensity, and smoking duration with the risk of incident and fatal prostate cancer.

Results: Compared with never smokers, current smokers had a reduced risk of prostate cancer (RR $=0.90,95 \%$ Cl: $0.83-0.97$ ), which was statistically significant for localised and low-grade disease, but not for advanced or high-grade disease. In contrast, heavy smokers ( $25+$ cigarettes per day) and men who had smoked for a long time $(40+$ years) had a higher risk of prostate cancer death $(\mathrm{RR}=1.81,95 \% \mathrm{Cl}: 1.11-2.93 ; \mathrm{RR}=1.38,95 \% \mathrm{Cl}: 1.01-1.87$, respectively).

Conclusion: The observation of an increased prostate cancer mortality among heavy smokers confirms the results of previous prospective studies.

*Correspondence: Dr S Rohrmann; E-mail sabine.rohrmann@ifspm.uzh.ch

Received 13 April 2012; revised 23 October 2012; accepted 29 October 2012; published online 20 November 2012

(c) 2013 Cancer Research UK. All rights reserved 0007-0920/13 
Prostate cancer is the most common incident cancer in males in developed countries (Ferlay et al, 2004). Owing to the large international variation in prostate cancer incidence and mortality rates, lifestyle is hypothesised to have a significant role in prostate cancer development, though the precise aetiological factors have not been identified. Cigarette smoking is still common in Europe, with up to $40 \%$ of the adult male population smoking in 2008 (European Health for All statistical database: http://www.who.dk/). Smoking is a well-known risk factor for several cancers, its relationship with prostate cancer risk is less clear. In a recent metaanalysis, current smoking was not associated with risk of prostate cancer, but there was an increased risk among heavy smokers (Huncharek et al, 2010). However, in that study, current smoking was associated with increased prostate cancer mortality (Huncharek et al, 2010) and a recent study showed that smoking at the time of diagnosis was related to a higher risk of prostate cancerspecific mortality (Gong et al, 2008).

To broaden our knowledge on the association of smoking with prostate cancer incidence and mortality, we investigated prospectively the association between cigarette smoking and prostate cancer incidence and mortality in the European Prospective Investigation into Cancer and Nutrition (EPIC).

\section{MATERIALS AND METHODS}

Study population. EPIC is a large prospective cohort study conducted in 23 centers in 10 European countries (Denmark (Aarhus, Copenhagen), France, Germany (Heidelberg, Potsdam), UK (Cambridge, Oxford), Greece, Italy (Florence, Naples, Ragusa, Turin, Varese), The Netherlands (Bilthoven, Utrecht), Norway, Spain (Asturias, Granada, Murcia, Navarra, San Sebastian), Sweden (Malmö, Umea)), including more than 500000 participants. The details of the recruitment process have been described previously (Riboli et al, 2002). In brief, in most centers, the participants were recruited from the general population. Italian and Spanish participants were recruited among blood donors, members of several health insurance programs, employees of several enterprises, civil servants, but also the general population. In Oxford, half of the cohort consisted of 'health conscious' subjects from across the UK. The cohorts of France, Naples, Norway, and Utrecht included women only (Riboli et al, 2002). All subjects gave written informed consent to use their questionnaire data and the Internal Review Boards of the International Agency for Research on Cancer and all EPIC recruitment centers approved the analyses based on EPIC participants.

Of the 148016 men without prevalent cancers (other than nonmelanoma skin cancer) eligible for analysis, men with incomplete follow-up and missing information on smoking status were excluded, leaving 145112 men available for analysis.

Exposure assessment. At study recruitment, detailed information was assessed on lifetime history of consumption of tobacco products. This included questions on smoking status (current, past, or never smoker), number of cigarettes currently smoked, average number of cigarettes smoked over their lifetime, the age when participants started and, if applicable, quit smoking.

Diet over the previous 12 months was assessed using dietary assessment instruments that were specifically developed for each participating country (Riboli et al, 2002). Baseline intake of energy and nutrients was calculated from the dietary instruments applied in each center (Riboli et al, 2002). Detailed information was also assessed on leisure-time, occupational, and household physical activity as well as education and marital status. Comparability of non-dietary questions was ensured by a set of core questions that were similar in all participating centers (Riboli et al, 2002). Height and weight were measured in all EPIC centers except for Oxford, where self-reported height and weight measurements were available (Riboli et al, 2002).

Outcome assessment. Cancer diagnoses were based on population registries in Denmark, Italy, the Netherlands, Spain, Sweden, and UK. An active follow-up through study subjects and next-of-kin information, the use of health insurance records, and cancer and pathology registries were used in Germany and Greece. Mortality data were obtained from either the cancer or mortality registries at the regional or national level. Cancer cases were identified by the end of the censoring periods ending between December 2004 and December 2008, depending on the most recent comparison of a center's database with the respective cancer registry. For Germany and Greece, the end of the follow-up was the last known contact, date of diagnosis, or date of death, whichever came first.

Definition of prostate cancer cases were based on the 10th revision of the International Classification of Diseases (ICD-10) and included all invasive malignant neoplasms, coded as C61. Information on tumour TNM stage and histological grade was collected from each center, where possible. Of 4623 incident prostate cancer cases, information was available on stage for $50 \%$ and on grade for $41 \%$. Tumours were classified as localised (T0/T1/ $\mathrm{T} 2$ and $\mathrm{N} 0 / \mathrm{NX}$ and $\mathrm{M} 0$, or stage coded in the recruitment center as localised; $n=1516$ ) or advanced (T3 or T4 and/or N1 + and/or M1, or stage coded in the recruitment center as advanced or metastatic; $n=808)$. Also, tumours were divided into lowhistological grade (Gleason score $2-7$ or equivalent (cases coded as well or moderately differentiated); $n=1517$ ) or high grade (Gleason score $\geqslant 8$ or equivalent (cases coded as poorly differentiated or undifferentiated); $n=396$ ). During the followup period, 432 fatal cases of prostate cancer were identified.

Statistical analysis. Cox proportional hazards regression was used to examine the association of smoking status at recruitment, smoking intensity (cigarettes per day in current smokers; mean lifetime number of cigarettes per day in former smokers), duration of smoking, and time since quit smoking. All analyses were conducted separately for former and current smokers. Smoking status was defined as never, former, current smokers; duration of smoking as $<10,10-19,20-29,30-39$, and $40+$ years; time since quit smoking as $<5,5-9,10-19$, and $20+$ years ago; and number of cigarettes smoked per day as $1-14,15-24$, and $25+$. Age was the primary time metric in the Cox proportional hazards models. Time at study entry was age at baseline, exit time was age when participants were diagnosed with cancer, died, were lost to followup, or were censored at the end of the follow-up period, whichever came first. Exit time for the analysis of prostate cancer mortality was age when participants died, were lost to follow-up, or were censored at the end of the follow-up period, respectively. The analyses were stratified by center and age at recruitment in 1-year categories. Multivariate models were adjusted for body weight and height at recruitment (as continuous variables), marital status (single/divorced/widowed, married/living together, missing), education (primary school or less, technical/professional school, secondary school, university, missing), and vigorous physical activity (none, $\leqslant 2 \mathrm{~h}$ per week, $>2 \mathrm{~h}$ per week, missing). Models that included additional adjustments for intake of energy, alcohol, red meat, processed meat, tomato sauce, vitamin E, and calcium did not materially alter the results and are not presented here. We also simultaneously adjusted for smoking intesity and duration, which, however, did not materially change the observed associations. Tests for trend were conducted using integer scores for categories of smoking intensity, smoking duration, and years since quit smoking. Sub-analyses were performed by stage and grade of prostate cancer, by age at recruitment $(<60, \geqslant 60)$, and by BMI $\left(<25, \geqslant 25 \mathrm{~kg} \mathrm{~m}^{-2}\right)$. We tested for interaction of age and BMI with smoking status in prostate cancer risk by including cross- 
product terms along with the main effect terms in the Cox regression model. The statistical significance of the cross-product terms was evaluated using the likelihood ratio test. We tested for heterogeneity by outcome strata (that is, low-grade $v s$ high-grade tumours; localised $v s$ advanced tumours) using the data augmentation method by Lunn and McNeil (1995). Heterogeneity between countries was assessed using likelihood $\chi^{2}$-tests. All analyses were conducted using SAS version 9.1 (SAS Institute, Cary, NC, USA).

\section{RESULTS}

Median follow-up time of the cohort was 11.9 (interquartile range 10.6-13.1) years. Former smokers were older and had a higher BMI than never and current smokers (Table 1). Current smokers had a higher intake of total energy, alcohol and red meat than never and former smokers and were more often physically inactive. Fomer smokers were more often married or lived together with a partner. Never smokers more often had a university degree than former and current smokers.

Current smokers had a significantly lower risk of prostate cancer than never smokers ( $\mathrm{RR}=0.90,95 \% \mathrm{CI}$ : 0.83-0.97; Table 2). This inverse association was evident for localised $(\mathrm{RR}=0.86,95 \% \mathrm{CI}$ : $0.75-0.99)$ and low-grade disease ( $R R=0.83,95 \%$ CI: $0.72-0.95)$, but not for advanced $(\mathrm{RR}=1.05,95 \% \mathrm{CI}$ : 0.87-1.27) and highgrade disease $(\mathrm{RR}=1.13,95 \% \mathrm{CI}$ : $0.86-1.47)$.

Among former and current smokers, smoking intensity and smoking duration were weakly inversely associated with prostate cancer, with similar associations observed for localised and lowgrade disease (Table 2). No associations were observed for advanced or high-grade disease. Former smokers who had smoked for at least 40 years had an increased risk of advanced prostate cancer compared with never smokers $(\mathrm{RR}=1.45$, 95\% CI: $1.05-$ 2.00). Also, men who had recently, that is, $<5$ years before recruitment, quit smoking had a non-significantly higher risk of advanced disease than never smokers $(\mathrm{RR}=1.32$, 95\% CI: 0.98 1.76), but the tests for trend were not statistically significant. No such associations were observed for high-grade disease (Table 2). Simultaneously adjusting dose for duration did not materially alter the observed associations (data not shown).

Current smoking was associated with a non-significant increased risk of prostate cancer mortality compared with never smokers $(\mathrm{RR}=1.27,95 \% \mathrm{CI}: 0.98-1.65)$. In particular, a high intensity of smoking $(\mathrm{RR}=1.81,95 \%$ CI: $1.11-2.93,25+$ cigarettes per day $v s$ non-smokers) and a long duration of smoking $(\mathrm{RR}=1.38,95 \% \mathrm{CI}: 1.01-1.87,40+$ years $v s$ non-smokers) were associated with a statistically significantly increased risk of prostate cancer death (Table 2). In a joint-effects analysis, we combined smoking status and smoking intensity (Figure 1) clearly showing an association between heavy current smoking and prostate cancer mortality, but no association for former smokers.

In a sub-analysis, we examined whether the categorization of tumours with Gleason sum of 7 into the group of high-grade cancer or as a separate group changed our results. For current smokers, the RR was 0.79 (95\% CI: 0.68-0.93) for tumours with Gleason sum $<7$ and 1.03 (95\% CI: 0.85-1.26) for tumours with Gleason sum $7+$. Using three groups for Gleason sum, the results were as follows: Gleason sum $<7$ : $\mathrm{RR}=0.79$ (95\% CI: 0.68-0.93); Gleason sum $=7$ : RR $=0.94$ (95\% CI: 0.71-1.25); and Gleason sum $8+\mathrm{RR}=1.13$ (95\% CI: $0.86-1.47)$.

We examined whether the associations between current smoking and prostate cancer incidence and mortality differed by country, but did not detect statistically significant heterogeneity (all $P$-values $>0.05)$. Also, results did not differ by BMI or age group $(P$-values for interaction $>0.05)$.

\section{DISCUSSION}

In this European cohort study, smoking was associated with a small reduction in the risk of prostate cancer, which was significant

Table 1. Baseline characteristics of male EPIC participants by smoking status at baseline, 1992-2000

\begin{tabular}{|c|c|c|c|}
\hline & $\begin{array}{l}\text { Never smokers } \\
\text { Median (Q1-Q3) }\end{array}$ & $\begin{array}{l}\text { Former smokers } \\
\text { Median (Q1-Q3) }\end{array}$ & $\begin{array}{l}\text { Current smokers } \\
\text { Median (Q1-Q3) }\end{array}$ \\
\hline Age at recruitment (years) & $51.4(42.6-58.8)$ & $54.8(48.7-61.1)$ & $51.9(45.1-58.0)$ \\
\hline $\mathrm{BMI}\left(\mathrm{kg} \mathrm{m}^{-2}\right)$ & $25.7(23.6-28.1)$ & $26.7(24.6-29.0)$ & $26.0(23.8-28.5)$ \\
\hline Body height $(\mathrm{cm})$ & $175.3(170.1-180.0)$ & $174.5(170.0-179.0)$ & $174.3(169.5-179.2)$ \\
\hline \multicolumn{4}{|l|}{ Marital status (\%) ${ }^{a}$} \\
\hline $\begin{array}{l}\text { Single } \\
\text { Married/living together } \\
\text { Divorced/separated } \\
\text { Widowed }\end{array}$ & $\begin{array}{r}14.3 \\
78.8 \\
5.4 \\
1.4\end{array}$ & $\begin{array}{r}6.4 \\
85.4 \\
6.1 \\
2.1\end{array}$ & $\begin{array}{r}12.9 \\
76.4 \\
9.0 \\
1.6\end{array}$ \\
\hline \multicolumn{4}{|c|}{ Vigorous physical activity (\%) } \\
\hline $\begin{array}{l}\text { None } \\
\leqslant 2 \mathrm{~h} \text { per week } \\
>2 \mathrm{~h} \text { per week }\end{array}$ & $\begin{array}{l}31.4 \\
21.1 \\
20.9\end{array}$ & $\begin{array}{l}35.1 \\
20.9 \\
22.4\end{array}$ & $\begin{array}{l}41.8 \\
17.2 \\
18.2\end{array}$ \\
\hline \multicolumn{4}{|c|}{ Highest level of education (\%) } \\
\hline $\begin{array}{l}\text { Primary school or less } \\
\text { Technical/professor school } \\
\text { Secondary school } \\
\text { University degree }\end{array}$ & $\begin{array}{l}25.8 \\
22.8 \\
17.0 \\
32.4\end{array}$ & $\begin{array}{l}31.5 \\
25.6 \\
14.9 \\
25.4\end{array}$ & $\begin{array}{l}36.6 \\
26.3 \\
15.9 \\
20.1\end{array}$ \\
\hline
\end{tabular}




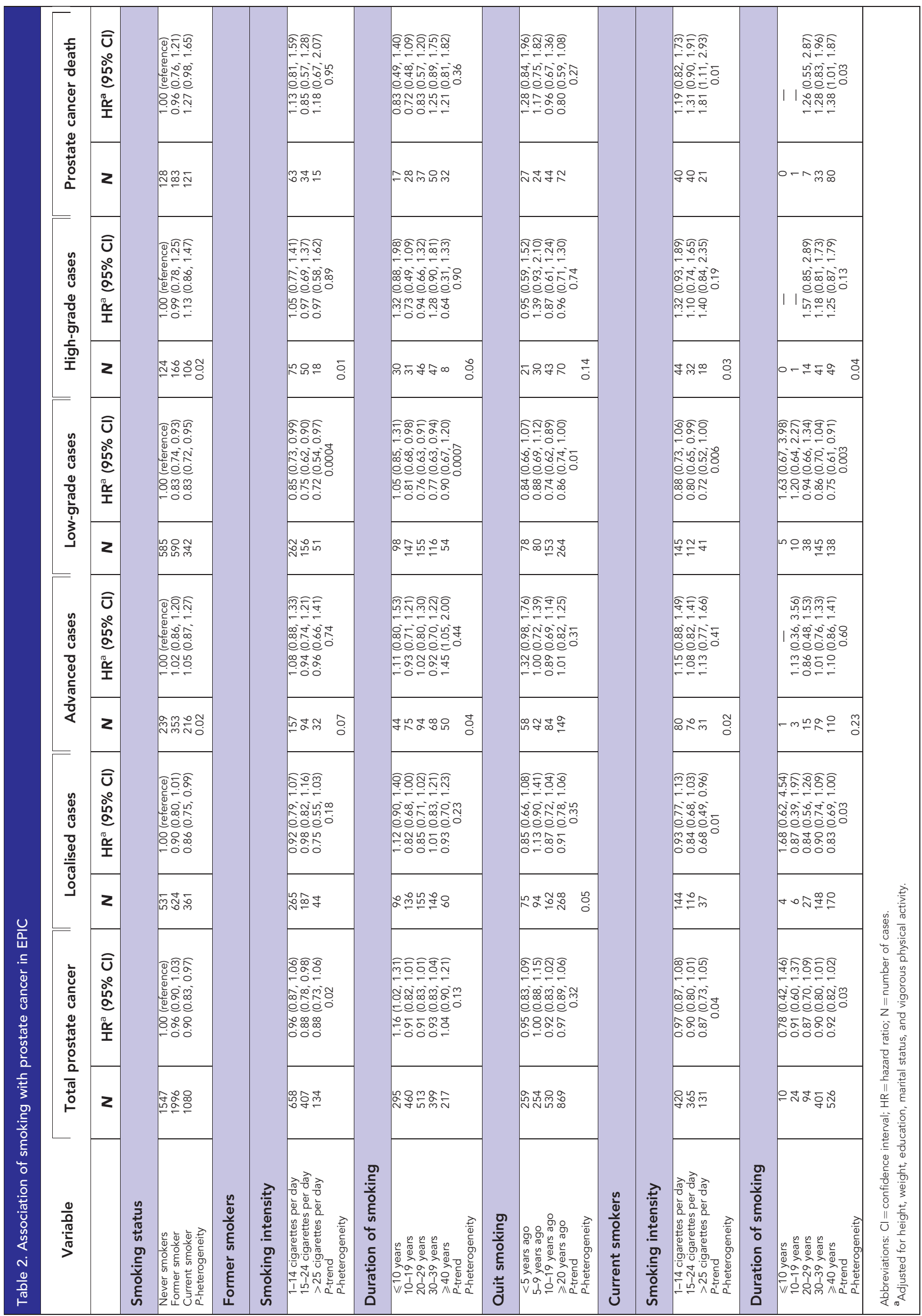




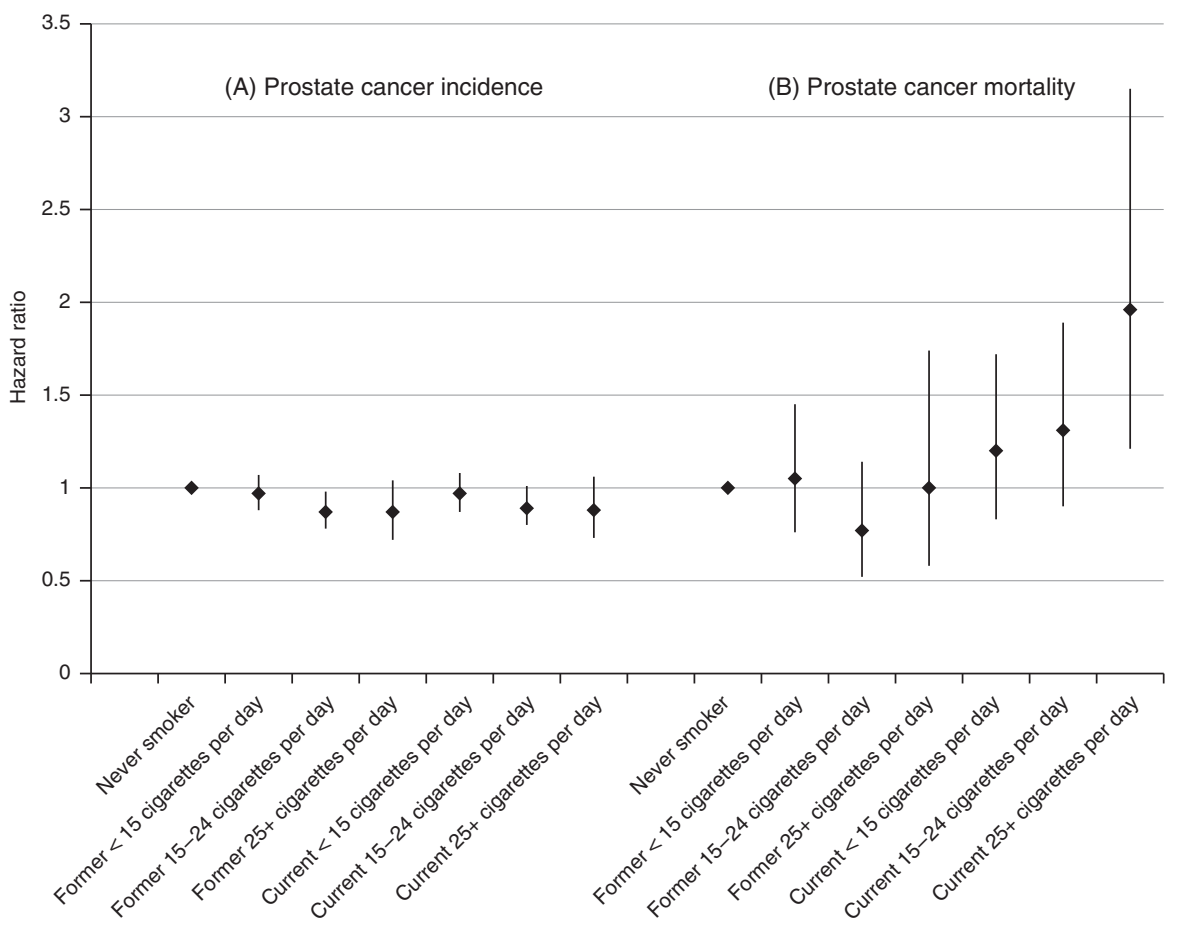

Figure 1. Association of smoking intensity (cigarettes per day by smoking status) and (A) prostate cancer incidence and (B) prostate cancer mortality in EPIC.

for less aggressive disease; there was no association between smoking and more aggressive incident disease. Smoking, in particular heavy smoking, was associated with a significant increase in risk of death from prostate cancer.

To date, most studies have not observed significant associations of smoking with overall prostate cancer incidence (Hickey et al, 2001; Huncharek et al, 2010). In the current study, we found that men who were smokers at recruitment had a $10 \%$ lower risk of prostate cancer overall than never smokers, whereas no significant association was seen for former smokers. However, the inverse association of current smoking with prostate cancer risk was confined to localised and low-grade disease. Similar inverse associations between smoking and low-grade prostate cancer have been reported in other studies (Giovannucci et al, 2007; Watters et al, 2009). It is possible that this association may reflect a detection bias, such that smokers are less likely to seek medical attention and undergo medical tests and therefore are less likely to be diagnosed with non-aggressive prostate cancer, or equally likely non-smokers may be more inclined to seek medical attention and be diagnosed with non-aggressive prostate cancer. We do not have information on prostate cancer testing in this study population and, thus, cannot evaluate the associations stratified by screening behaviour. However, in the NIH-AARP cohort, the inverse association between smoking and non-advanced prostate cancer was observed among men who had undergone DRE and PSA testing within the past 3 years and was, thus, independent of such screening (Giovannucci et al, 2007; Watters et al, 2009). The authors of that study speculated an inverse association between smoking and prostate cancer incidence might partly be explained by effects of smoking on circulating levels of insulin-like growth factor-I and sex hormone binding globulin (Giovannucci et al, 2007; Watters et al, 2009). However, further research is needed to clarify the true association between smoking and non-aggressive prostate cancer.

Heavy smokers had an increased risk of dying from prostate cancer, which is consistent with findings from previous US studies (Hsing et al, 1990; Hsing et al, 1991; Coughlin et al, 1996;
Rodriguez et al, 1997; Giovannucci et al, 1999; Giovannucci et al, 2007; Rohrmann et al, 2007; Batty et al, 2008; Watters et al, 2009; Weinmann et al, 2010). Zu and Giovannucci (2009) concluded that, compared with never smokers, current smoking is associated with an increased risk of about $30 \%$ for fatal prostate cancer; depending on the comparison, the increase in risk ranges from $14 \%$ to $30 \%$ in the meta-analysis of Huncharek et al, (2010). These estimates are similar to our estimate of a $27 \%$ higher risk of fatal prostate cancer comparing current with never smokers. An aggressive phenotype of prostate cancer may develop in smokers, for example due to mutations in genes such as p53 (Giovannucci et al, 1999). Continued exposure of the nascent prostate tumour to carcinogens present in cigarette smoke and the loss of glutathione S-transferase pi in prostate cancers (Lin et al, 2001), which metabolises and inactivates a number of carcinogens, might promote tumour progression (Roberts et al, 2003). Increased oxidative stress may promote an accumulation of somatic mutations in cancer cells and smoking-induced inflammation could also contribute to tumour progression (Gong et al, 2008). Two recent US studies have shown that men who smoked at diagnosis were more likely to progress (Joshu et al, 2011) and to die from the disease (Kenfield et al, 2011), but another study did not find an association of smoking with biochemical recurrence of the tumour (Moreira et al, 2010). However, all of these hypotheses implicate an effect of smoking via disease progression. For this to be true, one would also expect an association of heavy smoking with advanced disease. However, our findings do not support the hypothesis of an association between smoking and advanced or high-grade disease.

In our analysis, we were able to take into account several potential confounders of the association between cigarette smoking and prostate cancer risk, that is, body height and weight, education, marital status, and vigorous physical activity. The follow-up period in EPIC is relatively short (median of 11.9 years) compared with other cohort studies. However, this is not necessarily a disadvantage because some studies have shown that there seems to be a relationship between recent smoking and prostate cancer risk. A 
study by Hsing et al (1991) with 26 years of follow-up observed an attenuation of the association between smoking and prostate cancer mortality with increasing follow-up time. Similarly, an association between cigarette smoking and prostate cancer mortality was seen in the first 10 years of follow-up in a US cohort study but not when considering total follow-up time (Rohrmann et al, 2007). However, median follow-up time in our study among men who died of prostate cancer was only 5.0 years and when stratifying by follow-up time, we observed almost the same associations between smoking status at baseline and risk of dying from prostate cancer for follow-up periods of $0-<5$ years $(\mathrm{HR}=1.15,95 \% \mathrm{CI}: 0.89-1.50$ smokers $v s$ non-smokers $)$ and $5+$ years $(\mathrm{HR}=1.21,95 \% \mathrm{CI}$ : $0.90-1.61)$. When relying on a man's smoking status as reported at baseline, it is likely that there is less misclassification of smoking status earlier in follow-up than later in follow-up, when men may have subsequently quit smoking. A further limitation is possible misclassification of cause of death, that is, men with prostate cancer did not actually die of prostate cancer but of co-morbidity, however, the cause of death was attributed to prostate cancer. We relied on the underlying cause of death on death certificates and did not verify cause of death from medical records. However, in the Health Professionals Follow-up Study, re-examination of medical records by blinded reviewers had shown that deaths attributed to prostate cancer were likely to be truly prostate cancer specific (Giovannucci et al, 1999). Also, we do not have systematic information on prostate cancer sreening behaviour across the cohorts. We cannot exclude that screening behaviour differs between countries and is associated with the prevalence of smoking. The prevalence of smoking varies between the participating centers and countries, with rates below $25 \%$ in Sweden and Germany (as well as the British health-conscious cohort) and $>40 \%$ in Spain and Greece. Never-smoking rates ranged between $26 \%$ in Greece and $44 \%$ in Sweden. Thus, we cannot exclude that our results are affected by some residual confounding arising from differences in smoking prevalence and screening behaviour. Finally, we have conducted several subanalyses and, thus, cannot exclude the some of our findings might be due to chance.

In conclusion, smoking appears to be associated with a lower risk of less aggressive prostate cancer, while heavy smoking is associated with an increased risk of prostate cancer death. Future studies are warranted to examine whether these associations are due to different health-care seeking behaviour between smokers and non-smokers, and whether stopping smoking at the time of prostate cancer diagnosis will decrease the risk of dying from this disease as well as many other diseases.

\section{ACKNOWLEDGEMENTS}

This work was supported by European Commission Public Health and Consumer Protection Directorate 1993-2004; Research Directorate-General 2005-; Deutsche Krebshilfe (German Cancer Aid), Deutsches Krebsforschungszentrum (German Cancer Research Centre), German Federal Ministry of Education and Research; Danish Cancer Society; Health Research Fund (FIS) of the Spanish Ministry of Health, Spanish Regional Governments of Andalucia, Asturia, Basque Country, Murcia and Navarra and the Catalan Institute of Oncology; The CIBER en Epidemiología y Salud Pública and ISCIII RETIC (RD06/0020), Spain; Cancer Research UK; Medical Research Council, United Kingdom; Stroke Association, UK; British Heart Foundation; Department of Health, UK; Food Standards Agency, UK; Wellcome Trust, UK; Greek Ministry of Health; Greek Ministry of Education; Italian Association for Research on Cancer (AIRC); Italian National Research Council, Fondazione-Istituto Banco Napoli, Italy; Compagnia di
San Paolo; Dutch Ministry of Public Health, Welfare and Sports; World Cancer Research Fund; Swedish Cancer Society; Swedish Scientific Council; Regional Government of Skåne, Sweden.

\section{CONFLICT OF INTEREST}

The authors declare no conflict of interest.

\section{REFERENCES}

Batty GD, Kivimaki M, Gray L, Smith GD, Marmot MG, Shipley MJ (2008) Cigarette smoking and site-specific cancer mortality: testing uncertain associations using extended follow-up of the original Whitehall study. Ann Oncol 19: 996-1002.

Coughlin SS, Neaton JD, Sengupta A (1996) Cigarette smoking as a predictor of death from prostate cancer in 348,874 men screened for the Multiple Risk Factor Intervention Trial. Am J Epidemiol 143: 1002-1006.

Ferlay J, Bray F, Pisani P, Parkin D (2004) GLOBOCAN 2002: Cancer Incidence, Mortality and Prevalence Worldwide, IARC CancerBase No. 5. version $2.0 \mathrm{edn}$. IARC Press: Lyon.

Giovannucci E, Liu Y, Platz EA, Stampfer MJ, Willett WC (2007) Risk factors for prostate cancer incidence and progression in the health professionals follow-up study. Int J Cancer 121: 1571-1578.

Giovannucci E, Rimm EB, Ascherio A, Colditz GA, Spiegelman D, Stampfer MJ, Willett WC (1999) Smoking and risk of total and fatal prostate cancer in United States health professionals. Cancer Epidemiol Biomarkers Prev 8: $277-282$.

Gong Z, Agalliu I, Lin DW, Stanford JL, Kristal AR (2008) Cigarette smoking and prostate cancer-specific mortality following diagnosis in middle-aged men. Cancer Causes Control 19: 25-31.

Hickey K, Do KA, Green A (2001) Smoking and prostate cancer. Epidemiol Rev 23: 115-125.

Hsing AW, McLaughlin JK, Hrubec Z, Blot WJ, Fraumeni Jr JF (1991) Tobacco use and prostate cancer: 26-year follow-up of US veterans. Am J Epidemiol 133: 437-441.

Hsing AW, McLaughlin JK, Schuman LM, Bjelke E, Gridley G, Wacholder S, Chien HT, Blot WJ (1990) Diet, tobacco use, and fatal prostate cancer: results from the Lutheran Brotherhood Cohort Study. Cancer Res 50: 6836-6840.

Huncharek M, Haddock KS, Reid R, Kupelnick B (2010) Smoking as a risk factor for prostate cancer: a meta-analysis of 24 prospective cohort studies. Am J Public Health 100: 693-701.

Joshu CE, Mondul AM, Meinhold CL, Humphreys EB, Han M, Walsh PC, Platz EA (2011) Cigarette smoking and prostate cancer recurrence after prostatectomy. J Natl Cancer Inst 103(10): 835-838.

Kenfield SA, Stampfer MJ, Chan JM, Giovannucci E (2011) Smoking and prostate cancer survival and recurrence. JAMA 305: 2548-2555.

Lin X, Tascilar M, Lee WH, Vles WJ, Lee BH, Veeraswamy R, Asgari K, Freije D, van Rees B, Gage WR, Bova GS, Isaacs WB, Brooks JD, DeWeese TL, De Marzo AM, Nelson WG (2001) GSTP1 CpG island hypermethylation is responsible for the absence of GSTP1 expression in human prostate cancer cells. Am J Pathol 159: 1815-1826.

Lunn M, McNeil D (1995) Applying Cox regression to competing risks. Biometrics 51: 524-532.

Moreira DM, Antonelli JA, Presti Jr JC, Aronson WJ, Terris MK Kane CJ, Amling CL, Freedland SJ (2010) Association of cigarette smoking with interval to biochemical recurrence after radical prostatectomy: results from the SEARCH Database. Urology 76: $1218-1223$.

Riboli E, Hunt KJ, Slimani N, Ferrari P, Norat T, Fahey M, Charrondiere UR, Hemon B, Casagrande C, Vignat J, Overvad K, Tjonneland A, Clavel-Chapelon F, Thiebaut A, Wahrendorf J, Boeing H, Trichopoulos D, Trichopoulou A, Vineis P, Palli D, Bueno-De-Mesquita HB, Peeters PH, Lund E, Engeset D, Gonzalez CA, Barricarte A, Berglund G, Hallmans G, Day NE, Key TJ, Kaaks R, Saracci R (2002) European Prospective Investigation into Cancer and Nutrition (EPIC): study populations and data collection. Public Health Nutr 5: 1113-1124.

Roberts WW, Platz EA, Walsh PC (2003) Association of cigarette smoking with extraprostatic prostate cancer in young men. J Urol 169: 512-516. 
Rodriguez C, Tatham LM, Thun MJ, Calle EE, Heath Jr. CW (1997) Smoking and fatal prostate cancer in a large cohort of adult men. Am J Epidemiol 145: 466-475.

Rohrmann S, Genkinger JM, Burke A, Helzlsouer KJ, Comstock GW, Alberg AJ, Platz EA (2007) Smoking and risk of fatal prostate cancer in a prospective US study. Urology 69: 721-725.

Watters JL, Park Y, Hollenbeck A, Schatzkin A, Albanes D (2009) Cigarette smoking and prostate cancer in a prospective US cohort study. Cancer Epidemiol Biomarkers Prev 18: 2427-2435.

Weinmann S, Shapiro J, Rybicki B, Enger S, Van Den Eeden S Richert-Boe K, Weiss N (2010) Medical history, body size, and cigarette smoking in relation to fatal prostate cancer. Cancer Causes Control 21: 117-125.

$\mathrm{Zu} \mathrm{K}$, Giovannucci E (2009) Smoking and aggressive prostate cancer: a review of the epidemiologic evidence. Cancer Causes Control 20: 1799-1810.

This work is published under the standard license to publish agreement. After 12 months the work will become freely available and the license terms will switch to a Creative Commons AttributionNonCommercial-Share Alike 3.0 Unported License. 